Lancaster University

Management School

\author{
Economics Working Paper Series
}

2020/009

\title{
Corruption and mental health: Evidence from Vietnam
}

\author{
Smriti Sharma, Saurabh Singhal and Finn Tarp \\ The Department of Economics \\ Lancaster University Management School \\ Lancaster LA1 4YX \\ UK
}

(C) Authors

All rights reserved. Short sections of text, not to exceed two paragraphs, may be quoted without explicit permission, provided that full acknowledgement is given. 


\title{
Corruption and mental health: Evidence from Vietnam*
}

\author{
Smriti Sharma ${ }^{\dagger}$
}

\author{
Saurabh Singhal
}

Finn $\operatorname{Tarp}^{\S}$

May 2020

\begin{abstract}
While there is substantial corruption in developing countries, the costs imposed by corruption on individuals and households are little understood. This study examines the relationship between exposure to local corruption and mental health, as measured by depressive symptoms. We use two large data sets - one cross-sectional and one panel - collected across rural Vietnam. After controlling for individual and regional characteristics, we find strong and consistent evidence that day-to-day petty corruption is positively associated with psychological distress. Our results are robust to a variety of specification checks. Further, we find that the relationship between corruption and mental health is stronger for women, and that there are no heterogeneous effects by poverty status. Finally, using a difference-in-difference estimation strategy, we provide suggestive evidence that a recent highly profiled anti-corruption campaign had significant positive effects on mental health. Overall, our findings suggest that there may be substantial psychosocial and mental health benefits from efforts to reduce corruption and improve rural governance structures.
\end{abstract}

Keywords: Corruption, anti-corruption, mental health, depression, Vietnam

JEL classification codes: I3; I15; O12; D73; P3

*We thank Rob Gillanders for helpful comments. We are grateful for productive collaboration with the survey teams from CIEM, ILSSA, and the Ministry of Labour, Invalids and Social Affairs, Hanoi, Vietnam. Hoang Diem provided excellent research assistance. We also thank UNU-WIDER and the University of Copenhagen for financial support. These institutions had no involvement in study design, data collection, analysis, and or interpretation. The usual caveats apply.

${ }^{\dagger}$ Newcastle University; Email: smriti.sharma@newcastle.ac.uk

${ }^{\ddagger}$ Lancaster University \& IZA; Email: s.singhal1@lancaster.ac.uk

$\S$ University of Copenhagen; Email: finn.tarp@econ.ku.dk 


\section{Introduction}

Corruption is widespread in developing countries and there is universal agreement that corruption needs to be addressed to achieve inclusive economic growth (Olken and Pande, 2012). Reflecting this concern, combating corruption is a target under the United Nations' Sustainable Development Goals (SDGs). However, the gamut of costs imposed by corruption on individuals is little understood. In this paper, we assess the relationship between petty corruption and mental health in a developing country.

Being a victim of petty corruption can affect mental health for a variety of reasons. First, in low-income countries, harassment bribes represent a form of regressive income tax and are usually a non-trivial part of one's income, especially for poorer households. For instance, using data from the World Bank Enterprise Survey, Bai et al. (2019) find that even within countries, smaller firms pay higher bribes as a proportion of their income. Bribes therefore worsen economic conditions, and income loss has been shown to be detrimental to one's mental health (Adhvaryu et al. 2019; Christian et al., 2019). ${ }^{1}$ Second, the element of arbitrariness and uncertainty in bribe payments (the target, frequency and size of bribe) also creates anxiety, and can be particularly damaging for poor households. ${ }^{2}$

Third, harassment bribes induce feelings of helplessness and disenfranchisement as access to essential services such as health, education and public administration is dictated by the bribe-seeker who is a corrupt public official. This erodes trust in local governance and accountability structures, and/or reduce social capital in communities, thereby worsening mental health (Tavits, 2008). Finally, experiences of corruption may also reduce one's returns to labour effort through expropriation of resources, induce pessimistic beliefs about oneself,

\footnotetext{
${ }^{1}$ By worsening the supply of public goods such as access to healthcare, corruption, due to misallocation of resources, may also lead to poorer physical and mental health (Azfar and Gurgur, 2008; Dincer and Teoman, 2019).

${ }^{2}$ Shleifer and Vishny (1993) and Wei (1997) argue that the uncertainty characterizing corrupt transactions could also be of first-order importance in deterring investment.
} 
and lead to adverse mental health. de Quidt and Haushofer (2019) argue that this could also result in a 'depression poverty trap'.

Using first-hand cross-sectional and panel data collected across rural Vietnam, we find consistent evidence that day-to-day petty corruption is positively associated with psychological distress as measured by a standard depression index. We find that a one standard deviation increase in corruption is associated with a 7-12 percent increase in the CES-D index and a 20-24 percent increase in the likelihood of exhibiting symptoms of depression. These results are robust to controlling for several individual and community characteristics and a number of other checks. Worryingly, we also find the negative association between corruption and mental health to be stronger for women. We also examine the effects of anti-corruption efforts on mental health. The Communist Party of Vietnam (CPV) General Secretary Nguyen Phu Trong launched an unprecedented anti-corruption campaign in 2016, which resulted in several high-profile arrests and disciplining of government officials. Exploiting variation in exposure to corruption at the start of the campaign, we find evidence suggesting that this anti-corruption campaign had positive effects on mental health.

This paper contributes to two broad strands of research. The first is the literature examining the effects of corruption. Most studies have documented costs of corruption on economic growth, investment, provision of public goods, and firm profitability and innovation (e.g., Mauro, 1995; Paunov, 2016; Reinikka and Svensson, 2004; O’Toole and Tarp, 2014). However, only a few recent studies exist that have examined the link between corruption and mental health. Using cross-country data from Europe and Africa, these papers find a negative association between society-level and directly experienced corruption and indicators of mental wellbeing (Gillanders, 2016; van Deurzen, 2017). ${ }^{3}$ Our study uses individual and household-level data from one country and allows us to control for common influences at

\footnotetext{
${ }^{3}$ There is also some work showing that corruption negatively affects life satisfaction and happiness (Sulemana et al., 2017; Tavits, 2008).
} 
either the household or the village level. This is an improvement over other studies that pool data from a variety of countries and can only control for common country-level factors, which are not sufficiently disaggregated. This study is also the first to examine the potential effects of anti-corruption efforts on mental health. In doing so, it contributes to a nascent literature studying the effects of anti-corruption policies in developing countries (e.g., Hao et al., forthcoming; Xu and Yano, 2017).

Secondly, we also contribute to the emerging literature on the causes of poor mental health in developing countries. Poor mental health and associated disorders are an important component of the disease burden in developing countries (Patel, 2007; WHO, 2017). Those with mental health problems are less likely to engage in the labour market and have lower labour productivity (Frijters et al., 2014). Previous studies have found negative effects of economic shocks such as exposure to financial crises, jobs and income loss, and lack of access to social protection on mental health (e.g., Adhvaryu et al., 2019; Baird et al., 2013; Friedman and Thomas, 2009; Marcus, 2013). Similarly, other socioeconomic conditions such as conflict and crime have also been found to adversely affect mental health (Dustmann and Fasani, 2016; Singhal, 2019). Studies also show that poverty or material deprivation affects cognitive bandwidth and functioning (Mani et al., 2013; Schilbach et al., 2016). Given that government corruption is distinctly higher in poorer countries, the poverty-cognition link could be exacerbated by corruption, thereby imposing a cost on mental health in developing countries.

Vietnam provides a relevant context for this study. Since the initiation of the Doi Moi reforms in 1986, Vietnam has made impressive gains in economic and social well-being, headlined by a dramatic fall in poverty (McKay et al., 2018). However, the reforms (privatization, trade liberalization, deregulation, etc.) that shifted the economy from a state-led one to one relying on the private sector, also likely had some negative side effects. First, the country ranks 
among the most corrupt and least transparent in the world. The main forms of corruption in Vietnam are grease money to provide basic tasks or services, the illegal privatisation of state property, and the selling of state power. The first, i.e., petty corruption for accessing basic public goods and services, is the most dominant and visible (Bai et al., 2019). In 2017, Vietnam was ranked 107 out of 180 countries on Transparency International's index of perceived corruption in the public sector and had a score well below the average. Corruption is also an important part of the cost of doing business (Gueorguiev and Malesky, 2012; Rand and Tarp, 2012). For instance, Gueorguiev and Malesky (2012) show that 35 percent of Vietnamese businesses paid bribes to compete for government procurement contracts, 23 percent paid bribes to expedite business registration, and 70 percent paid bribes during customs procedures.

Second, improvements in the Vietnamese health sector have not kept pace with the needs of the rapidly growing economy, and mental health has not been a priority area. While prevalence of mental disorders is not estimated to be disproportionate to those in other neighbouring countries (Vuong et al., 2011), there is unequal access to mental health care services and primary care providers are inadequately trained (WHO, 2006; Giang et al., 2010). Results of this study can help inform policy regarding the allocation of resources for mental health care.

The paper is organized as follows. Section 2 describes the sample and the empirical specification. Section 3 presents the results and Section 4 describes the effects of the anti-corruption campaign on mental health. Finally, Section 5 provides concluding remarks. 


\section{Data and estimation strategy}

\section{$2.1 \quad$ Data}

This study uses data from two sources to assess the relationship between corruption and mental health in Vietnam. The first data were collected as part of an experimental study (Vietnam Social Capital Study (VSCS), henceforth) conducted in May-June 2017 in 56 rural communes across 22 provinces in the Red River Delta (in northern Vietnam) and Mekong River Delta (in southern Vietnam). Figure A1 in the online Appendix depicts the survey provinces. We obtained listings of households in the communes, and the study team contacted the households to advertise the study and to encourage participation. Two sessions with 12 subjects each were organized in each commune, leading to a sample of 1,344 subjects.

After the experiments, enumerators conducted individual face-to-face interviews with all subjects to complete a post-experiment questionnaire. This collected information on background characteristics such as age, gender, education, ethnicity, marital status and asset ownership.

As part of the post-experiment questionnaire, respondents were presented with statements to elicit individual experiences and beliefs about corruption in the public sector with specific reference to bribery to obtain land titles, to get a government job, to receive medical treatment etc. Respondents were asked how much they agreed with each of the six presented statements on a 4-point scale where 1 meant 'agree completely', 2 meant 'somewhat agree', 3 meant 'disagree' and 4 meant 'disagree completely'. We recode responses to each statement as 1 if the subject indicates agreement and 0 otherwise, and then construct the individuallevel corruption index as the sum of the responses to these six statements. ${ }^{4}$ We standardize

\footnotetext{
${ }^{4}$ These statements are listed in Table A1 in the online Appendix. These statements were taken from
} 
the corruption index (by subtracting the mean and dividing by its standard deviation) and use that as our key explanatory variable.

To measure mental health of the respondents, the questionnaire also included a module on the 10-item Center for the Epidemiological Studies of Depression short form (CES-D). The CES-D, developed by Radloff (1977), is one of the main scales used to measure depressive symptoms internationally and a number of epidemiological studies show that it strongly predicts clinical diagnoses of depression and anxiety disorders (Weissman et al., 1977). Respondents were asked to indicate how often they had certain feelings in the last week on a 0-3 scale - "never (0 days in a week)", "sometimes (1-2 days of the week)", "often (3-4 days of the week)", and "all the time (5-7 days of the week)" ${ }^{5}$ A higher CES-D score reflects poorer mental health. We use the CES-D scale to construct two dependent variables. First, we use the composite score of the 10 questions (ranging from 0 to 30). Second, a score of 10 and above (out of a maximum of 30) is used as an indicator for the presence of significant depressive symptoms. We use this threshold to construct a dummy variable, 'severe stress', that takes the value 1 for CES-D scores greater than or equal to 10 , and 0 otherwise. This latter measure of mental health has been used widely in other studies (e.g., de Quidt and Haushofer, 2019; Singhal, 2019).

We exclude a small number of subjects with missing responses to the depressive symptoms module, the corruption statements, or the socioeconomic characteristics. This results in a sample of 1,318 respondents in the VSCS.

We also use the 2016 and 2018 waves of the Vietnam Access to Resources Household Survey (VARHS hereafter). The VARHS is a long-running panel survey of almost 3,500 rural

a summary indicator of the quality of governance titled 'Vietnam Provincial Governance and Public Administration Performance Index' (PAPI). This index is constructed annually from surveys conducted across Vietnam, to measure the performance of central and local governments in governance, public administration and public service delivery.

${ }^{5}$ CES-D questions are provided in Table A2 in the online Appendix. 
households conducted every second year since 2006 in 12 provinces across Vietnam (see Ayala-Cantu et al., 2017 for details). Mental health is also measured in the VARHS 2016 and 2018 waves using the 10-item CES-D index. The CES-D is only administered to the primary respondent of the household - the household head or his/her spouse in most cases. With these data, we also construct the composite CES-D index score as well as the "severe stress' dummy variable as the outcome variables. With regards to corruption, all households that reported operating at least one non-farm business are asked if corruption imposed a cost on their business. The responses are on a 4-point scale where 1 meant 'very large', 2 meant 'large', 3 meant 'small' and 4 meant 'no effect'. For ease of interpretation, we construct a continuous measure of 'corruption costs' by reverse coding these responses to range from 0 to 3 where 0 indicates 'no effect' and 3 indicates 'very large' effects. In the regression analysis we use the standardized version of this corruption measure as the explanatory variable. Finally, we use a balanced panel, only keeping households that operate a household enterprise in both rounds. This yields a sample of 956 observations across both rounds.

\subsection{Estimation strategy}

We use OLS regressions to estimate the relationship between corruption and mental health in the VSCS data using the following equation:

$$
Y_{i j}=\alpha_{0}+\alpha_{1} \operatorname{Corr}_{i j}+\sum_{l=2}^{K} \alpha_{l} X_{i j}+v_{j}+\epsilon_{i j}
$$

where, $Y_{i j}$ is the outcome measure for individual $i$ residing in commune $j$. The two outcomes are the composite CES-D score and the 'severe stress' indicator, as measured in the first dataset. The coefficient $\alpha_{1}$ captures the association between corruption experiences $\left(\right.$ Corr $\left._{i j}\right)$ and mental well-being. $X_{i s j}$ includes individual-level controls such as age, gender (takes a 
value 1 for female), education (takes a value 1 for those who have completed high school), marital status (takes a value 1 if married), ethnicity (takes a value 1 for the ethnic majority Kinh), poverty status (takes a value 1 for those classified as poor by the government), and household's asset ownership. In addition, we include commune fixed effects $\left(v_{j}\right)$ to account for common factors that affect all individuals within a commune (such as infrastructure, ethnic composition). Finally, $\epsilon_{i j}$ corresponds to a random error term. We allow for arbitrary correlation at the level of the commune by clustering the standard errors at the commune level.

In the estimations above, we do not make claims of causality. While we have controlled for all common commune-level factors and several individual-level observables, there may be individual-level unobserved factors that could influence mental health and be related to corruption experiences (e.g., household structure). Similarly, the OLS estimate of $\alpha_{1}$ may also be biased due to reverse causality if respondents with poorer mental health are more likely to recall the incidence of corruption. We attempt to reduce this bias by using the VARHS panel data to estimate the following household fixed effects model:

$$
Y_{i t}=\beta_{0}+\beta_{1} C C_{i t}+\beta_{2} T_{t}+\sum_{l=3}^{K} \beta_{l} X_{i t}+\eta_{i}+\nu_{i t}
$$

where, $Y_{i t}$ is the mental health of the primary respondent in household $i$ at time $t$. $C C_{i t}$ is the self-reported cost of corruption on the household enterprise at time $t$, and the parameter of interest is $\beta_{1}$. The vector $X_{i t}$ includes respondent characteristics (gender, age, marital status, primary school completion dummy), household poverty status, and time-varying indicator variables to control for household exposure to the following shocks in the preceding two years: natural disasters (floods, droughts, etc.), pest attacks, and health shocks (death of a household member or illness). All household-specific time-invariant characteristics are 
captured by the household fixed effect, $\eta_{i}$. By conditioning on household fixed effects, $\eta_{i}$, we are only exploiting within-household variation in the burden of corruption to estimate the relationship with mental health. Moreover, this strategy also eliminates regional effects that are unlikely to change over the two-year survey period (e.g., access to healthcare) and are potentially correlated with both mental health and corruption. We also control for any unobserved country-wide macroeconomic conditions at the time of the surveys using year fixed effects $\left(T_{t}\right) . \quad \nu_{i t}$ is an idiosyncratic error term. We cluster the standard errors at the level of the household to allow household responses to be correlated over time.

Before moving to the results it is important to discuss some caveats. In particular, one may be concerned about the interpretation of results as both mental health and corruption measures are self-reported. First, if there is random error in the explanatory variable (selfreported corruption) or if there is a general tendency to under-report corruption, then the results will be biased towards zero. Second, if measurement error in the dependent variables is random, then it will only reduce the precision of the estimates, without biasing the results. Still, measurement error could be a concern if it correlated with respondents' characteristics. However, to the extent that the reporting bias is constant over time, then the household fixed effects used in equation 2 would account for it. As results in Table 4 show, we still find corruption to be negatively associated with mental health, indicating that misreporting is unlikely to be driving the results. 


\section{Results}

\subsection{Descriptive statistics}

Summary statistics of the VSCS dataset are presented in Table 1. Figure A2 in the online Appendix presents the distribution of the CES-D scores for the analysis sample. The Cronbach's $\alpha$ is 0.66 , which indicates a reasonably high level of internal consistency. Panel A of Table 1 shows that the average score on the CES-D is 5.05 for the sample and 12 percent of the sample exhibits symptoms of severe stress.

Panel B of Table 1 shows summary statistics for the corruption indicators, the key explanatory variables. Agreement with the various indicators of corruption differs across the measures. We find that 37 percent of the sample believes that bribes are required to get a government job. A correspondingly high percentage of respondents believe that bribes are required in the health and education sectors (32 and 25 percent, respectively).

Finally, Panel C shows summary statistics for the other covariates used in the analysis. ${ }^{6}$ Overall, the sample of subjects was well-balanced in terms of gender with 52 percent of subjects being female. The average age is around 38 years while 81 percent were married. Approximately 54 percent of the sample had completed high school education. On average, households these subjects belonged to owned 9 out of 16 assets listed in the questionnaire. ${ }^{7}$ Around 8 percent of them were classified as being poor according to the government author-

\footnotetext{
${ }^{6}$ Table A3 in the online Appendix shows the means of the observed characteristics of the VSCS sample and those of the rural population of the same 22 provinces as computed from the Vietnam Household and Living Standards Survey (VHLSS) 2016. We find that the two samples are quite similar though the experiment subjects are more educated. That there is positive selection based on education into participation in such experiments has also been shown in other work.

${ }^{7}$ The questionnaire elicited whether households owned each of the following assets: bicycle, black and white TV, colour TV, scooter/motorcycle/moped, landline telephone, mobile phone, electric fan, radio/stereo, pump set, refrigerator, computer/laptop, internet access, washing machine, cooler/air conditioner, car/truck/van, and flush toilet.
} 
ities. Ninety-three percent of the sample belonged to the Kinh majority ethnic group. ${ }^{8}$

$$
\text { [Table } 1 \text { about here] }
$$

Summary statistics of the VARHS data are presented in Table A4 of the online Appendix. We find that for the balanced panel of households that operated non-farm businesses in 2016 and 2018, mental health improved and the costs of corruption declined over time. The average score on the CES-D declined from 6.94 in 2016 to 5.42 in 2018. Similarly, the proportion of households exhibiting symptoms of severe stress fell from 0.26 in 2016 to 0.16 in 2018. Correspondingly, the average costs of corruption index fell from 0.5 to 0.36 during the same period.

We graphically examine the association between corruption and mental health using the VSCS dataset in Figure 1. Figures 1A and 1B illustrate the relationship between corruption and CES-D index and with likelihood of severe stress respectively. Both figures show a clear positive relationship, indicating that psychological stress increases with corruption.

[Figure 1 about here]

\subsection{Regression analyses and robustness}

Table 2 shows the key results of the paper using the VSCS dataset. The dependent variable in column 1 is the CES-D index. In column 2 the dependent variable is an indicator for severe mental stress. As shown in both columns, corruption is positively and significantly associated with the mental health index. We find that a one standard deviation increase in the corruption index increases the CES-D score by 0.6 units, and the likelihood of severe stress by 2.4 percentage points. Given a sample mean of 5.02 for the CES-D index and

\footnotetext{
${ }^{8}$ There are 54 officially recognized ethnic groups in Vietnam. The Kinh, the ethnic majority, constitute around 85 per cent of the population. The ethnic minorities largely reside in the Central Highlands and the Northern Uplands, and are therefore, slightly underrepresented in this sample.
} 
12 percent for severe stress, this translates into a 12 percent and a 20 percent increase, respectively.

[Table 2 about here]

These results are robust to the inclusion of controls in columns 3 and 4 . We also find that females have lower mental health relative to males. This is supported by global evidence on the female mental health penalty (WHO, 2017) and other studies in Vietnam (Giang et al., 2010; Leggett et al., 2012). We also find that individuals from poor households report significantly lower mental health. This is in line with a large emerging literature that finds income losses to worsen mental health, and that cash transfers and other social security schemes improve mental health (Angeles et al., 2019; Baird et al., 2013; Haushofer and Shapiro, 2016).

We examine whether the relationship between corruption and mental health is different based on gender and poverty status. In columns 1 and 2 of Table 3, we find that the effect of corruption on the CES-D index is greater for females as compared to males (column 1) but this is not so for the severe stress indicator (column 2). This is consistent with other evidence that shows that females' mental health is more susceptible to external shocks (Dustmann and Fasani, 2016). Corruption can further compound the negative relationship between income/wealth and mental health, as the poor may not have access to mitigation strategies as the rich do. In columns 3 and 4 we find that the poor who are more exposed to corruption have lower mental health, but the results are not statistically significant.

[Table 3 about here]

The results in Table 2 are also robust to a number of sensitivity checks. First, we check whether the results are driven by a particular component of the mental health index. Results in Table A5 in the online Appendix show that exposure to corruption is significantly related 
to eight of the ten components.

Second, we also check the robustness of the result to a principal component analysis of the CES-D questions, where we retain the first factor. Using the standardized value of this factor as the dependent variable, we once again find exposure to corruption to be significantly related to lower mental health $(\beta($ s.e. $)=0.19(0.03))$.

Third, we check if the results are sensitive to the construction of the corruption index (Table A6 of the online Appendix). Instead of recoding the six corruption statements into binary indicators, we use the corruption statements on the original 1-4 scale where 1 indicates complete disagreement and 4 indicates complete agreement. The index is then formed by summing all responses and ranges from 6-24, and then standardized. In columns 1 and 2, we find that corruption continues to be significantly associated with poorer mental health. It is also possible that our results are driven by some respondents who report high levels of corruption. To check for this, we construct a corruption dummy that takes the value 1 if the respondent reports agreement with at least one of the corruption statements and 0 otherwise. This binary measure also mitigates concerns of reverse causality, i.e., the possibility that people reporting worse mental health may be more likely to recall more instances of corruption. Once again, we find that our results are robust to this reclassification of the corruption measure (columns 3 and 4).

Fourth, we have so far assumed that all dimensions of corruption have a similar relationship with mental stress. We now relax this assumption by considering each of the six corruption measures individually in Tables A7 and A8 in the online Appendix. All six corruption measures are associated with an increase in the CES-D index (Table A7). Similarly, in Table A8 we find that 4 out of the 6 corruption measures are significantly associated with an increase in the probability of severe stress.

Fifth, we also assess the possible degree of omitted variable bias using the approach of Oster 
(2019). The method computes how important the explanatory power of unobservables would have to be relative to the observables to fully explain the coefficient of interest. Using this method, we find that for the CES-D index, the explanatory power of the unobservables would have to be 4.4 times higher than that of the observables and negatively correlated with observables to be able to explain the results. Similarly in the case of the severe stress indicator. These results contradict the standard assumption that unobservables are positively correlated with observables and are equally important, giving us reasonable confidence that omitted variable bias is not affecting our results.

Finally, we corroborate our findings using an alternative data set (VARHS) and estimation strategy. We use a balanced panel of households that operated a household enterprise in 2016 and 2018, along with a fixed effects model (equation 2) outlined in Section 2.2 to estimate results exploiting within-household variation in exposure to corruption over time. The main explanatory variable is a standardized measure of the intensity of the costs of corruption. The results using these data and estimation strategy are reported in columns 1 and 2 of Table 4. We find that a one standard deviation increase in the costs of corruption is positively associated with a 0.45 unit increase in the CES-D index score (or a 7.2 percent increase over the sample mean). In column 2 we find that a 1 standard deviation increase in corruption is associated with a 5 percentage point increase in severe stress. Given a sample mean of 21 percent, this translates into a 23.8 percent increase. These results are fairly similar to those noted above in Table 2 .

[Table 4 about here]

We also construct a variable that takes the value 1 if the household reports any costs of corruption and use that as the explanatory variable in columns 3 and 4 of Table 4 . These results show that corruption reduces mental health at the extensive margin as well. Together, these findings show that there is strong consistent evidence that corruption is associated with 
an increase in mental stress.

\section{Effects of recent anti-corruption efforts on mental health}

In this section, we assess the impact of the CPV General Secretary's 2016 anti-corruption campaign on mental health using the VARHS data. The campaign resulted in the arrests of several high-profile government officials, executives of state enterprises, and others in the private sector (Le, 2017; Meyers, 2018). Between January 2016 and August 2018, it is estimated that 56 government officials were disciplined over corruption and 500 individuals prosecuted and sentenced in 40 corruption cases (Hoa, 2018). Several new rules have been put in place to prevent government officials from misusing their power (Reuters, 2019). Observational reports suggest that this campaign has reduced corruption (Hoa, 2018; Hiep, 2019).

Recall that in the VARHS data 'corruption costs' on household enterprises range from 0 to 3 where 0 indicates 'no effect' and 3 indicates 'very large effect'. In this case, the campaign would matter more for households that were more affected by corruption before the campaign. We exploit this variation in the exposure of households to use a difference-in-difference approach, where we compare the difference in mental health of affected and unaffected households before and after the campaign. The panel regressions take the following form:

$$
Y_{i t}=\gamma_{0}+\gamma_{1} \text { High corruption }_{i} * \text { Post }_{t}+\gamma_{2} T_{t}+\sum_{l=3}^{K} \gamma_{l} X_{i t}+\eta_{i}+\omega_{i t}
$$

where $Y_{i t}$ is the mental health of the primary respondent in household $i$ at time $t$, and $T_{t}$ and $\eta_{i}$ are year and household fixed effects, respectively. As the anti-corruption efforts started 
in 2016, we take 2018 to be the post-treatment period (captured by the indicator variable Post $_{t}$. High corruption $_{i}$ is a dummy variable that takes value 1 for all households that report any amount of corruption in 2016. The assumption is that the households that could potentially benefit from the anti-corruption campaign "treatment" were those that reported their household enterprises suffering from corruption at baseline. The coefficient of interest, $\gamma_{1}$, estimates the impact of the campaign. We cluster the standard errors at the level of the household..$^{9}$

\section{[Table 5 about here]}

The results presented in Table 5 show that the anti-corruption campaign significantly improved mental health. Column 1 shows that, relative to households unaffected by corruption, the CES-D index of household that experienced corruption decreased by 1.15 units due to the campaign. Given the control mean of 6.73, this translates into a 17 percent improvement. The effects on the severe stress indicator are in the same direction (7.6 percentage points, or 31 percent over the control mean) but not statistically significant $(p$-value $=0.11)$. Overall, these results suggest that the anti-corruption campaign had meaningful positive effects on mental health. While this analysis is preliminary in nature, the results are interesting and worthy of further research.

\section{Conclusion}

This paper contributes to the limited literature examining the linkages between corruption and mental health. First, using a cross-sectional sample of over 1,300 respondents across 22 provinces in rural Vietnam, we find strong evidence that day-to-day petty corruption

\footnotetext{
${ }^{9} \mathrm{An}$ important assumption of this analysis is that in the absence of the anti-corruption campaign, the trends in mental well-being would have been similar between households that were affected and unaffected by corruption in 2016 .
} 
is positively associated with psychological distress. Second, we find similar results from a panel data of non-farm household enterprise owners from 12 provinces in rural Vietnam. These results are also robust to a variety of other checks. While our study does not make a definitive claim of causality between corruption and mental health, the robustness of our results indicate that daily stress factors like corruption are important determinants of mental health in developing countries.

We also find that the relationship between corruption and mental health is stronger for women. Given that women are often marginalised and have limited access to mental health services, this indicates that concerted effects to insulate women from corruption can have large payoffs. Furthermore, there is increasing evidence that welfare of children is closely associated with the psychological well-being of their caregivers, who more likely to be women. This implies that improving mental health of women can have broader impacts on society by limiting inter-generational transmission of poor mental health.

Fighting corruption remains high on the current policy agenda of the Vietnamese government, as evidenced by the unprecedented anti-corruption campaign launched by CPV General Secretary in 2016. While reductions in economic costs and inefficiencies have been long recognized as the potential benefits of efforts to mitigate corruption, the findings presented here suggest that there may be large gains in mental health as well. To that end, we recommend rigorous evaluations of psychosocial interventions in poor institutional settings. 


\section{References}

Adhvaryu, A., Fenske, J., \& Nyshadham, A. 2019. Early life circumstance and adult mental health. Journal of Political Economy, 127, 1516-1549.

Angeles, G., de Hoop, J., Handa, S., Kilburn, K., Milazzo, A., \& Peterman, A. 2019. Government of Malawi's unconditional cash transfer improves youth mental health. Social Science ES Medicine, 225, 108-119.

Ayala-Cantu, L., T. Beni, T. Markussen, G. Narciso, C. Newman, A. Singh, S. Singhal, F. Tarp, \& Zille, H. 2017. Characteristics of the Vietnamese Rural Economy: Evidence from a 2016 Rural Household Survey in 12 Provinces of Vietnam. Helsinki: UNU-WIDER.

Azfar, O., \& Gurgur, T. 2008. Does corruption affect health outcomes in the Philippines? Economics of Governance, 9(3), 197-244.

Bai, J., Jayachandran, S., Malesky, E.J., \& Olken, B. 2019. Firm growth and corruption: Empirical evidence from Vietnam. Economic Journal, 129, 651-677.

Baird, S., De Hoop, J., \& Özler, B. 2013. Income shocks and adolescent mental health. Journal of Human Resources, 48(2), 370-403.

Christian, C., Hensel, L., \& Roth, C. 2019. Income shocks and suicides: Causal evidence from Indonesia. Review of Economics and Statistics, 101(5), 905-920.

de Quidt, J., \& Haushofer, J. 2019. Depression through the Lens of Economics: A Research Agenda. In C.B. Barrett, M.R. Carter \& J-P., Chavas (eds.) The Economics of Poverty Traps.

Dincer, O., \& Teoman, O. 2019. Does corruption kill? Evidence from half a century infant mortality data. Social Science \& Medicine, 232, 332-339.

Dustmann, C., \& Fasani, F. 2016. The effect of local area crime on mental health. The 
Economic Journal, 126, 978-1017.

Friedman, J., \& Thomas, D. 2008. Psychological health before, during, and after an economic crisis: Results from Indonesia, 1993-2000. World Bank Economic Review, 23(1), 57-76.

Frijters, P., Johnston, D.W., \& Shields, M.A. 2014. The Effect Of Mental Health On Employment: Evidence From Australian Panel Data. Health Economics, 23(9), 1058-1071.

Giang, K.B., Dzung, T.V., Kullgren, G., \& Allebeck, P. 2010. Prevalence of mental distress and use of health services in a rural district in Vietnam. Global Health Action, 3(1), 2025.

Gillanders, R. 2016. Corruption and anxiety in Sub-Saharan Africa. Economics of Governance, 17(1), 47-69.

Gueorguiev, D., \& Malesky, E. 2012. Foreign investment and bribery: A firm-level analysis of corruption in Vietnam. Journal of Asian Economics, 23(2), 111-129.

Hao, Z., Liu, Y., Zhang, J., \& Zhao, X. forthcoming. Political connection, corporate philanthropy and efficiency: Evidence from Chinas anti-corruption campaign. Journal of Comparative Economics

Haushofer, J., \& Shapiro, J. 2016. The Short-term Impact of Unconditional Cash Transfers to the Poor: Experimental Evidence from Kenya. Quarterly Journal of Economics, 131(4), 1973-2042.

Hoa, X. 2018. Corruption dwindling in Vietnam, asserts Party leader. VNExpress International, 17 August.

Hiep, Le H. 2019. The Impact of Vietnam's Anti-corruption Campaign on the Real Estate Sector. SEAS Yusof Ishak Institute.

Le, Q. 2017. Vietnam sacks top official for PetroVietnam 'violation'. BBC Vietnamese, 8 
May.

Leggett, A., Zarit, S. H., Nguyen, N. H., Hoang, C. N., \& Nguyen, H. T. (2012). The influence of social factors and health on depressive symptoms and worry: A study of older Vietnamese adults. Aging $\&$ Mental Health, 16(6), 780-786.

Mani, A., Mullainathan, S., Shafir, E., \& Zhao, J. 2013. Poverty Impedes Cognitive Function. Science, 341(6149), 976-80.

Marcus, J. 2013. The effect of unemployment on the mental health of spouses - Evidence from plant closures in Germany. Journal of Health Economics, 32(3), 546-558.

Mauro, P. 1995. Corruption and growth. Quarterly Journal of Economics, 110(3), 681712.

McKay, A. D., Singhal, S., \& Tarp, F. 2018. Welfare dynamics in rural Viet Nam: Learning from regular, high-quality panel data. WIDER Working Paper No. 2018/169.

Meyers, J. 2018. Vietnam's corruption crackdown is targeting the powerful. Has it gone too far? Los Angeles Times, 16 January.

Olken, B.A., \& Pande, R. 2012. Corruption in developing countries. Annual Review of Economics, 4, 479-509.

Oster, E. 2019. Unobservable selection and coefficient stability: Theory and evidence. Journal of Business \& Economic Statistics, 37(2), 187-204.

O'Toole, C. M., \& Tarp, F. 2014. Corruption and the efficiency of capital investment in developing countries. Journal of International Development, 26(5), 567-597.

Patel, V. 2007. Mental health in low- and middle-income countries. British Medical Bulletin, 81-82(1), 81-96.

Paunov, C. 2016. Corruption's asymmetric impacts on firm innovation. Journal of Develop- 
ment Economics,118, 216-231.

Radloff, L.S. 1977. The CES-D Scale. Applied Psychological Measurement, 1(3), 385401.

Rand, J., \& Tarp, F. 2012. Firm-level corruption in Vietnam. Economic Development \& Cultural Change, 60(3), 571-595.

Reinikka, R., \& Svensson, J. 2004. Local capture: Evidence from a central government transfer program in Uganda. Quarterly Journal of Economics, 119(2), 679-705.

Reuters. 2019, Sept 26. Vietnam Communist Party takes aim at corrupt rising stars.

Schilbach, F., Schofield, H., \& Mullainathan, S. 2016. The psychological lives of the poor. American Economic Review: Papers \& Proceedings, 106(5), 435-440.

Shleifer, A., \& Vishny, R.W. 1993. Corruption. Quarterly Journal of Economics, 108, 599617.

Singhal, S. 2019. Early life shocks and mental health: The long-term effect of war in Vietnam. Journal of Development Economics, 141, 102244.

Sulemana, I., Iddrisu, A.M., \& Kyoore, J.E. 2017. A micro-level study of the relationship between experienced corruption and subjective wellbeing in Africa. Journal of Development Studies, 53(1), 138-155.

Tavits, M. 2008. Representation, corruption and subjective well-being. Comparative Political Studies, 41(12), 1607-1630.

Van Deurzen, I. 2017. And justice for all: Examining corruption as a contextual source of mental illness. Social Science $E 3$ Medicine, 173, 26-34.

Vuong, D. A., Van Ginneken, E., Morris, J., Ha, S.T., \& Busse, R. (2011). Mental health in Vietnam: Burden of disease and availability of services. Asian Journal of Psychiatry, 4(1), 
65-70.

Wei, S. 1997. Why is corruption so much more taxing than tax? Arbitrariness kills. NBER Working Paper 6255.

Weissman, M. M., Sholomskas, D., Pottenger, M., Prusoff, B. A., \& Locke, B. Z. 1977. Assessing depressive symptoms in five psychiatric populations: a validation study. American Journal of Epidemiology, 106(3), 203-214.

WHO, 2006. WHO-AIMS report on mental health system in Vietnam. Geneva: World Health Organization.

WHO. 2017. Depression and other common mental disorders: Global health estimates. Geneva: World Health Organization.

Xu, G., \&Yano, G. 2017. How does anti-corruption affect corporate innovation? Evidence from recent anti-corruption efforts in China. Journal of Comparative Economics, 45, 498519. 
Figure 1: Relationship between mental health and different levels of corruption
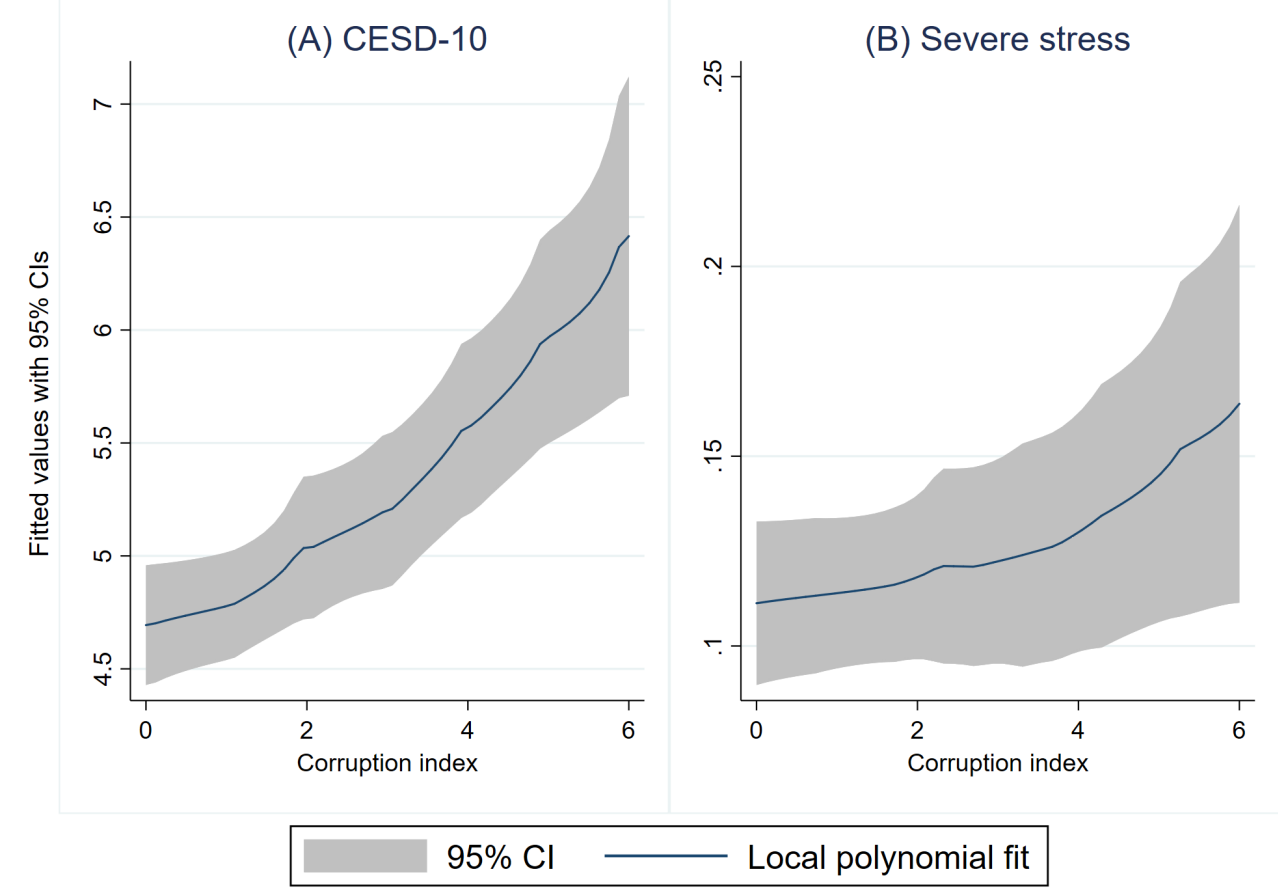

Source: Authors' illustration based on the Vietnam Social Capital Survey (VSCS) data. 
Table 1: Summary statistics

\begin{tabular}{lcc}
\hline & Mean & SD \\
\hline Panel A: Mental health outcomes & & \\
CESD-10 index & 5.02 & 3.71 \\
Severe stress & 0.12 & 0.32 \\
Panel B: Corruption variables & & \\
Officials divert funds for private benefit & 0.16 & 0.37 \\
Bribes for land titles & 0.28 & 0.45 \\
Bribes in hospitals & 0.32 & 0.47 \\
Bribes to school teachers & 0.25 & 0.44 \\
Bribes for construction permits & 0.20 & 0.40 \\
Bribes for govt. jobs & 0.37 & 0.48 \\
Corruption index & 1.59 & 1.77 \\
Panel C: Control variables & & \\
Female & 0.52 & 0.50 \\
Age & 38.74 & 10.59 \\
Kinh & 0.93 & 0.25 \\
Completed High School & 0.54 & 0.50 \\
Poor Household & 0.08 & 0.27 \\
Number of assets & 9.04 & 2.60 \\
Married & 0.81 & 0.39 \\
Observations & 1318 & \\
\hline
\end{tabular}

Notes: This table is based on the Vietnam Social Capital Survey (VSCS) data. The maximum possible score on CES-D index is 30 . Severe stress is an indicator for CES-D index $\geq 10$. The maximum number of assets is 16. Poor household is an indicator variable for respondent's household being classified as poor by the government. Kinh is the ethnic majority group. 
Table 2: Corruption and mental health

\begin{tabular}{|c|c|c|c|c|}
\hline & $\begin{array}{l}\text { CES-D Index } \\
\text { (1) }\end{array}$ & $\begin{array}{c}\text { Severe Stress } \\
(2)\end{array}$ & $\begin{array}{c}\text { CES-D Index } \\
\text { (3) }\end{array}$ & $\begin{array}{c}\text { Severe Stress } \\
\text { (4) }\end{array}$ \\
\hline Corruption index (z-score) & $\begin{array}{c}0.603^{* * *} \\
(0.101)\end{array}$ & $\begin{array}{l}0.024^{* *} \\
(0.011)\end{array}$ & $\begin{array}{c}0.621^{* * *} \\
(0.096)\end{array}$ & $\begin{array}{l}0.028^{* *} \\
(0.011)\end{array}$ \\
\hline Female & & & $\begin{array}{c}0.620^{* * *} \\
(0.163)\end{array}$ & $\begin{array}{c}0.052^{* * *} \\
(0.018)\end{array}$ \\
\hline Age & & & $\begin{array}{c}0.017 \\
(0.012)\end{array}$ & $\begin{array}{l}0.003^{* *} \\
(0.001)\end{array}$ \\
\hline Kinh & & & $\begin{array}{l}-0.237 \\
(0.683)\end{array}$ & $\begin{array}{c}0.013 \\
(0.060)\end{array}$ \\
\hline Completed High School & & & $\begin{array}{c}0.192 \\
(0.217)\end{array}$ & $\begin{array}{l}-0.002 \\
(0.018)\end{array}$ \\
\hline Poor Household & & & $\begin{array}{l}0.817^{* *} \\
(0.373)\end{array}$ & $\begin{array}{l}0.067^{*} \\
(0.036)\end{array}$ \\
\hline Number of assets & & & $\begin{array}{l}-0.090 \\
(0.056)\end{array}$ & $\begin{array}{l}-0.007 \\
(0.005)\end{array}$ \\
\hline Married & & & $\begin{array}{l}-1.314^{* * *} \\
(0.305)\end{array}$ & $\begin{array}{c}-0.089^{* * *} \\
(0.027)\end{array}$ \\
\hline Commune Fixed Effects & Yes & Yes & Yes & Yes \\
\hline $\begin{array}{l}\text { Mean of dep. var. } \\
\mathrm{N}\end{array}$ & $\begin{array}{l}5.02 \\
1318\end{array}$ & $\begin{array}{l}0.12 \\
1318\end{array}$ & $\begin{array}{l}5.02 \\
1318\end{array}$ & $\begin{array}{l}0.12 \\
1318\end{array}$ \\
\hline
\end{tabular}

Notes: This table uses data from the Vietnam Social Capital Survey (VSCS). Severe stress is an indicator for CES-D index $\geq 10$. Standard errors clustered at the commune level are reported in parentheses. * significant at $10 \%,{ }^{* *}$ significant at $5 \%,{ }^{* * *}$ significant at $1 \%$. 
Table 3: Corruption and mental health: Heterogeneity

\begin{tabular}{lcccc}
\hline & CES-D Index & $\begin{array}{c}\text { Severe Stress } \\
(1)\end{array}$ & $\begin{array}{c}\text { CES-D Index } \\
(2)\end{array}$ & $\begin{array}{c}\text { Severe Stress } \\
(3)\end{array}$ \\
\hline Corruption index (z-score) & $0.354^{* *}$ & 0.022 & $0.613^{* * *}$ & $0.027^{* *}$ \\
& $(0.155)$ & $(0.015)$ & $(0.096)$ & $(0.011)$ \\
Corruption index*Female & $0.501^{*}$ & 0.011 & & \\
& $(0.251)$ & $(0.023)$ & & \\
Corruption index*Poor & & & 0.097 & 0.008 \\
& & & $(0.361)$ & $(0.037)$ \\
Controls & Yes & Yes & Yes & Yes \\
Commune Fixed Effects & Yes & Yes & Yes & Yes \\
\hline Mean of dep. var. & 5.02 & 0.12 & 5.02 & 0.12 \\
$\mathrm{~N}$ & 1318 & 1318 & 1318 & 1318 \\
\hline
\end{tabular}

Notes: This table uses data from the Vietnam Social Capital Survey (VSCS). Severe stress is an indicator for CES-D index $\geq 10$. Controls include age, gender, education, ethnicity, marital status, household assets, and household poverty status. Poor is an indicator variable for respondent's household being classified as poor by the government. Standard errors clustered at the commune level are reported in parentheses. * significant at $10 \%,{ }^{* *}$ significant at $5 \%,{ }^{* * *}$ significant at $1 \%$. 
Table 4: Corruption and mental health: VARHS Data

\begin{tabular}{lcccc}
\hline & $\begin{array}{c}\text { CES-D Index } \\
(1)\end{array}$ & $\begin{array}{c}\text { Severe Stress } \\
(2)\end{array}$ & $\begin{array}{c}\text { CES-D Index } \\
(3)\end{array}$ & $\begin{array}{c}\text { Severe Stress } \\
(4)\end{array}$ \\
\hline Corruption costs (z-score) & $0.453^{* *}$ & $0.050^{* *}$ & & \\
& $(0.197)$ & $(0.020)$ & & $0.920^{* *}$ \\
Corruption dummy & & & $(0.378)$ & $0.088^{* *}$ \\
& & & Yes & Yes \\
Household controls & Yes & Yes & Yes & Yes \\
Household Fixed Effects & Yes & Yes & Yes & Yes \\
Year Fixed Effects & Yes & Yes & 6.18 & 0.21 \\
\hline Mean of dep. var. & 6.18 & 0.21 & 956 & 956 \\
N & 956 & 956 & &
\end{tabular}

Notes: This table uses the Vietnam Access to Resources Household Survey (VARHS) data. Severe stress is an indicator for CES-D index $\geq 10$. Corruption costs index ranges from 0 to 3 . Corruption dummy is an indicator for Corruption costs $>0$. Controls include respondent's age, gender, primary school completion, marital status, household poverty status, and household exposure to pest, natural disaster, and illness/death shocks. Standard errors clustered at household level are reported in parentheses. ${ }^{*}$ significant at $10 \%,{ }^{* *}$ significant at $5 \%,{ }^{* * *}$ significant at $1 \%$. 
Table 5: Anti-corruption campaign and mental health

\begin{tabular}{lcc}
\hline & CES-D Index & $\begin{array}{c}\text { Severe Stress } \\
(1)\end{array}$ \\
\hline High corruption*Post & $-1.144^{* *}$ & -0.076 \\
& $(0.473)$ & $(0.048)$ \\
Household controls & Yes & Yes \\
Household Fixed Effects & Yes & Yes \\
Year Fixed Effects & Yes & Yes \\
\hline Mean of control dep. var. & 6.73 & 0.24 \\
$\mathrm{~N}$ & 956 & 956 \\
\hline
\end{tabular}

Notes: This table reports results of the difference-in-differences estimation strategy described in Section 4 using the Vietnam Access to Resources Household Survey (VARHS) data. Severe stress is an indicator for CES-D index $\geq 10$. High corruption is a dummy variable that takes the value 1 for households that reported corruption in 2016. Post is an indicator for the post-treatment period of 2018. Controls include respondent's age, gender, primary school completion, marital status, household poverty status, and household exposure to pest, natural disaster, and illness/death shocks. Standard errors clustered at household level are reported in parentheses. ${ }^{*}$ significant at $10 \%,{ }^{* *}$ significant at $5 \%,{ }^{* * *}$ significant at $1 \%$. 


\section{Online Appendices for:}

Corruption and mental health: Evidence from Vietnam 
Figure A1: Map of the Vietnam Social Capital Survey (VSCS) study provinces

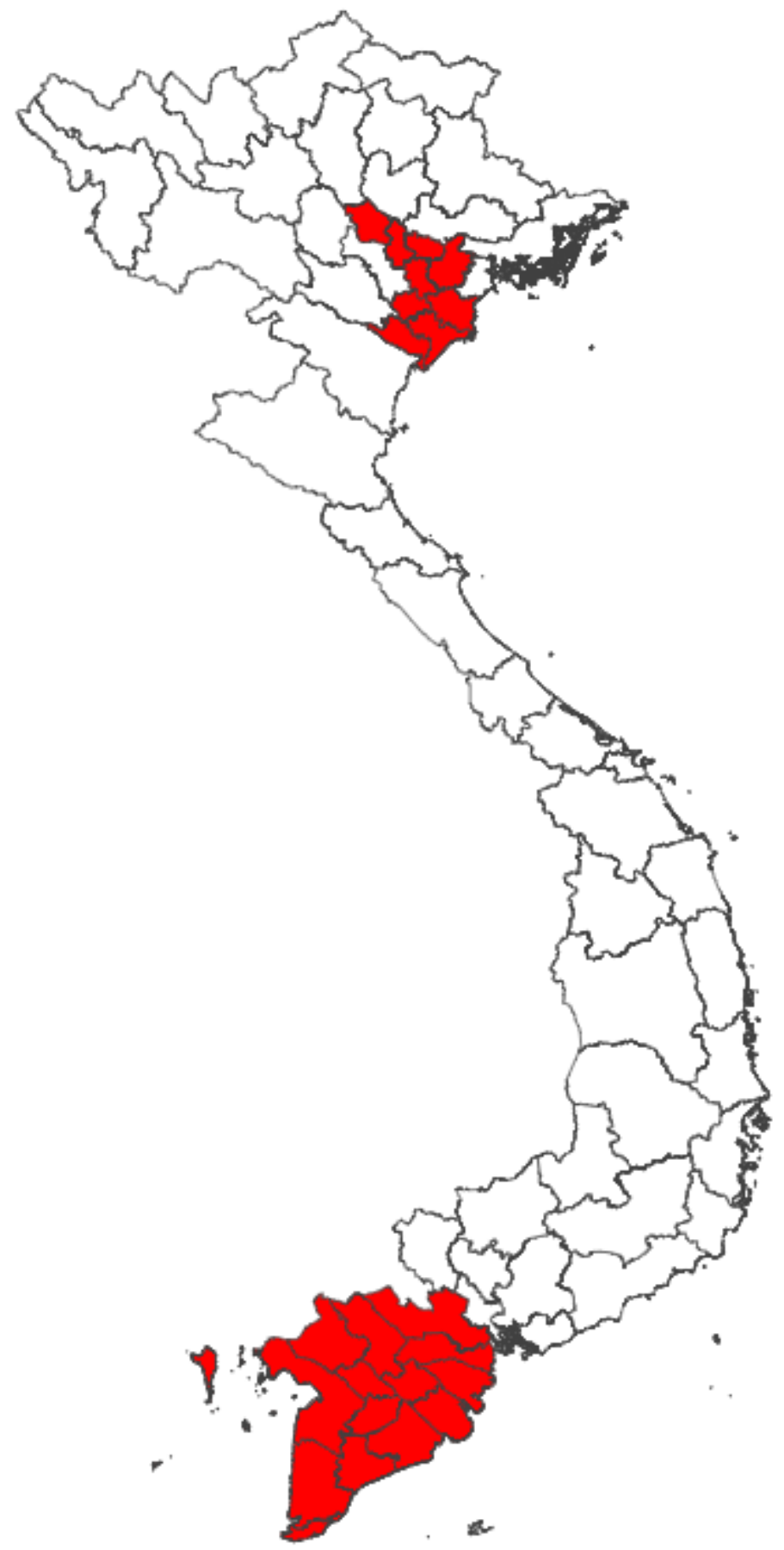

Source: Authors' illustration. 
Figure A2: Density of CES-D score for the Vietnam Social Capital Survey (VSCS) sample

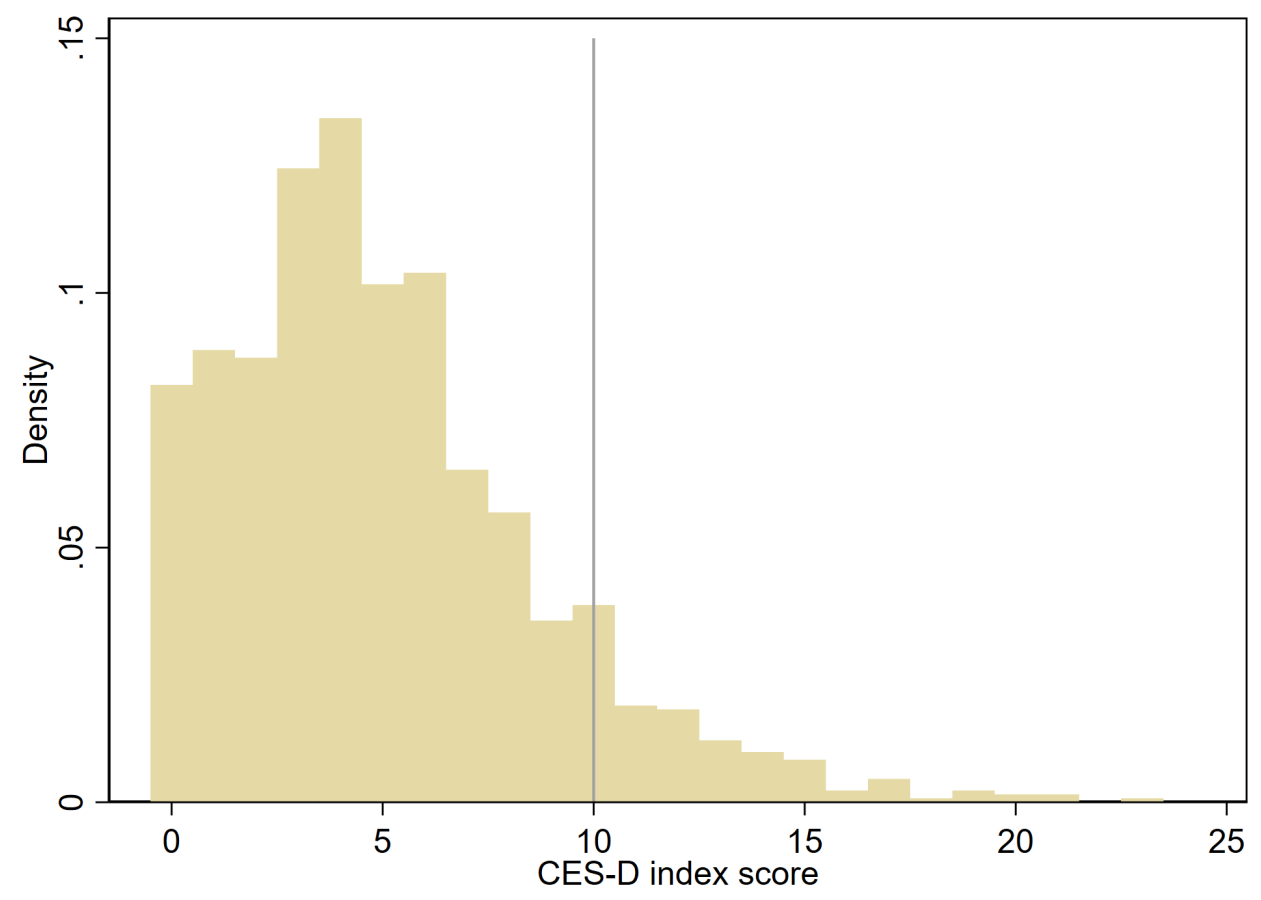

Notes: The grey line at a CES-D score of 10 represents the threshold for severe stress. 


\section{Table A1: Corruption statements}

\section{Statement}

1 In my commune/ward, officials divert funds from the state budget for their personal benefit

2 People have to pay bribes in order to obtain a land title

3 People like me have to bribe to receive medical treatment in the district's hospitals

4 Parents have to pay bribes to teachers for their children to be better attended at the primary school nearest to my house

5 In my commune/ward, officials receive kickbacks in exchange for approval of construction permits

6 In order to get a job in the government, people have to pay a bribe

Notes: In the Vietnam Social Capital Survey (VSCS) respondents were asked how much they agreed with each of the six presented statements on a 4-point scale where 1 meant 'agree completely', 2 meant 'somewhat agree', 3 meant 'disagree' and 4 meant 'disagree completely'. For the main analysis we recode responses to each statement as 1 if the subject indicates agreement and 0 otherwise, and then construct the individual-level corruption index as the sum of the responses to these six statements. 
Table A2: CES-D Index questions

$\begin{array}{ll}\text { In } & \text { the last } 7 \text { days .... } \\ 1 & \text { how often did you sleep well? } \\ 2 & \text { how often were you happy? } \\ 3 & \text { how often did you have trouble concentrating in what you were doing? } \\ 4 & \text { how often did you feel hopeful about the future? } \\ 5 & \text { how often did you feel that everything you did was an effort? } \\ 6 & \text { how often did you feel lonely? } \\ 7 & \text { how often did you feel depressed? } \\ 8 & \text { how often did you feel that you could not "get going"? } \\ 9 & \text { how often were you bothered by things that don't usually bother you? } \\ 10 & \text { how often did you feel fearful? }\end{array}$

Notes: Respondents were asked to indicate how often they had these feelings in the last week on a four-scale metric - "never (0 days in a week)", "sometimes (1-2 days of the week)", "often (3-4 days of the week)", and "all the time (5-7 days of in a week)". These responses are coded from 0 to 3 respectively. The response scale is reversed for the positive questions, so that they have the same sign as those negative questions. 
Table A3: Comparison of VSCS sample with the VHLSS

\begin{tabular}{lcc}
\hline Variable & $\begin{array}{c}\text { VSCS Sample } \\
(1)\end{array}$ & $\begin{array}{c}\text { VHLSS 2016 } \\
(2)\end{array}$ \\
\hline Female & 0.52 & 0.52 \\
Age & 38.76 & 42.43 \\
High school education & 0.54 & 0.27 \\
Married & 0.81 & 0.78 \\
Kinh & 0.93 & 0.95 \\
Poor household & 0.08 & 0.07 \\
\hline Observations & 1344 & 6438 \\
\hline
\end{tabular}

Notes: This table compares the Vietnam Social Capital Survey (VSCS) sample characteristics with those in the Vietnam Household and Living Standards Survey (VHLSS) 2016. The VHLSS 2016 figures are based on information collected from respondents of rural communes in the same 22 provinces as the experimental sample. The VHLSS did not collect information on the same assets reported in Table 1 . Poor household is an indicator variable for respondent's household being classified as poor by the government. 
Table A4: Summary statistics of VARHS data

\begin{tabular}{lccccc}
\hline & \multicolumn{2}{c}{2016} & & \multicolumn{2}{c}{2018} \\
\cline { 2 - 2 } & Mean & SD & & Mean & SD \\
& $(1)$ & $(2)$ & & $(3)$ & $(4)$ \\
\hline Panel A: Mental health outcomes & & & & \\
CESD-10 index & 6.94 & 4.22 & & 5.42 & 3.81 \\
Severe stress & 0.26 & 0.44 & & 0.16 & 0.37 \\
Panel B: Corruption variables & & & & \\
Corruption costs & 0.50 & 0.69 & & 0.36 & 0.59 \\
Corruption dummy & 0.40 & 0.49 & & 0.31 & 0.46 \\
Panel C: Control variables & & & & \\
Female & 0.44 & 0.50 & & 0.43 & 0.50 \\
Age & 50.74 & 12.74 & & 51.61 & 12.71 \\
Primary school education & 0.87 & 0.33 & & 0.79 & 0.41 \\
Married & 0.85 & 0.36 & & 0.86 & 0.35 \\
Poor household & 0.06 & 0.23 & & 0.02 & 0.15 \\
Natural shock & 0.07 & 0.26 & & 0.05 & 0.22 \\
Health shock & 0.09 & 0.29 & & 0.01 & 0.11 \\
Pest attack & 0.06 & 0.24 & & 0.06 & 0.24 \\
Observations & 478 & & & 478 & \\
\hline
\end{tabular}

Notes: The maximum possible score on CES-D index is 30. Severe stress is an indicator for CES-D index $\geq 10$. Corruption costs index ranges from 0 to 3 . Corruption dummy is an indicator for Corruption costs index $>0$. Poor household is an indicator variable for respondent's household being classified as poor by the government. 
Table A5: Robustness check: CES-D index components

\begin{tabular}{|c|c|c|c|c|c|}
\hline & Sleepless & Unhappy & $\begin{array}{c}\text { Trouble } \\
\text { concentrating }\end{array}$ & $\begin{array}{c}\text { Future } \\
\text { hopeless }\end{array}$ & $\begin{array}{c}\text { Everything } \\
\text { an effort }\end{array}$ \\
\hline & (1) & $(2)$ & $(3)$ & (4) & (5) \\
\hline \multirow[t]{2}{*}{ Corruption index (z-score) } & $0.099^{* * *}$ & $0.103^{* * *}$ & $0.081^{* * *}$ & -0.001 & -0.030 \\
\hline & $(0.027)$ & $(0.023)$ & $(0.022)$ & $(0.027)$ & $(0.035)$ \\
\hline \multirow[t]{3}{*}{ Mean of dep. var. } & 0.64 & 0.48 & 0.69 & 0.50 & 0.91 \\
\hline & Felt lonely & Depressed & $\begin{array}{l}\text { Could not } \\
\text { "get going" }\end{array}$ & $\begin{array}{c}\text { Easily } \\
\text { bothered }\end{array}$ & Fearful \\
\hline & $(6)$ & $(7)$ & $(8)$ & $(9)$ & $(10)$ \\
\hline \multirow[t]{2}{*}{ Corruption index (z-score) } & $0.083^{* * *}$ & $0.055^{* * *}$ & $0.049^{* * *}$ & $0.120^{* * *}$ & $0.061^{* *}$ \\
\hline & $(0.021)$ & $(0.018)$ & $(0.016)$ & $(0.022)$ & $(0.023)$ \\
\hline Mean of dep. var. & 0.32 & 0.22 & 0.20 & 0.58 & 0.47 \\
\hline Controls & Yes & Yes & Yes & Yes & Yes \\
\hline Commune Fixed Effects & Yes & Yes & Yes & Yes & Yes \\
\hline $\mathrm{N}$ & 1318 & 1318 & 1318 & 1318 & 1318 \\
\hline
\end{tabular}

Notes: This table uses data from the Vietnam Social Capital Survey (VSCS). Controls include age, gender, education, ethnicity, marital status, household assets, and household poverty status. Standard errors clustered at the commune level are reported in parentheses. ${ }^{*}$ significant at $10 \%,{ }^{* *}$ significant at $5 \%,{ }^{* * *}$ significant at $1 \%$. 
Table A6: Robustness: alternative corruption measures

\begin{tabular}{lcccc}
\hline & CES-D Index & Severe Stress & CES-D Index & Severe Stress \\
& $(1)$ & $(2)$ & $(3)$ & $(4)$ \\
\hline Contin. corruption index (z-score) & $0.690^{* * *}$ & $0.040^{* * *}$ & & \\
& $(0.115)$ & $(0.012)$ & & $0.974^{* * *}$ \\
Corruption dummy & & & $(0.171)$ & $(0.018)$ \\
Female & $0.647^{* * *}$ & $0.054^{* * *}$ & $0.623^{* * *}$ & $0.052^{* * *}$ \\
Age & $(0.168)$ & $(0.019)$ & $(0.172)$ & $(0.019)$ \\
Kinh & 0.015 & $0.002^{* *}$ & 0.013 & $0.002^{* *}$ \\
Completed High School & $(0.012)$ & $(0.001)$ & $(0.012)$ & $(0.001)$ \\
Poor Household & -0.220 & 0.015 & -0.279 & 0.011 \\
& $(0.678)$ & $(0.059)$ & $(0.694)$ & $(0.061)$ \\
Number of assets & 0.215 & -0.001 & 0.225 & -0.001 \\
& $(0.224)$ & $(0.018)$ & $(0.221)$ & $(0.018)$ \\
Married & $0.768^{* *}$ & $0.064^{*}$ & $0.870^{* *}$ & $0.070^{*}$ \\
Commune Fixed Effects & $(0.377)$ & $(0.036)$ & $(0.372)$ & $(0.036)$ \\
\hline Mean of dep. var. & $-0.097^{*}$ & -0.008 & -0.092 & -0.007 \\
N & $(0.057)$ & $(0.005)$ & $(0.056)$ & $(0.005)$ \\
& $-1.346^{* * *}$ & $-0.091^{* * *}$ & $-1.284^{* * *}$ & $-0.088^{* * *}$ \\
& $(0.305)$ & $(0.027)$ & $(0.307)$ & $(0.027)$ \\
& Yes & Yes & Yes & Yes \\
\hline
\end{tabular}

Notes: This table uses data from the Vietnam Social Capital Survey (VSCS). In columns 1 and 2, corruption is a continuous measure in the 6-24 range. In columns 3 and 4, corruption dummy takes the value 1 if the respondent expressed agreement with any corruption statement and 0 otherwise. Severe stress is an indicator for CESD-10 index $\geq 10$. Standard errors clustered at the commune level are reported in parentheses. ${ }^{*}$ significant at $10 \%,{ }^{* *}$ significant at $5 \%, * * *$ significant at $1 \%$. 
Table A7: Detailed corruption measures and CES-D index

\begin{tabular}{|c|c|c|c|c|c|c|}
\hline & (1) & $(2)$ & (3) & (4) & $(5)$ & (6) \\
\hline Officials divert funds for private benefit & $\begin{array}{c}1.075^{* * *} \\
(0.290)\end{array}$ & & & & & \\
\hline Bribes for land titles & & $\begin{array}{c}0.750^{* * *} \\
(0.238)\end{array}$ & & & & \\
\hline Bribes in hospitals & & & $\begin{array}{c}0.850^{* * *} \\
(0.202)\end{array}$ & & & \\
\hline Bribes to school teachers & & & & $\begin{array}{c}0.990^{* * *} \\
(0.244)\end{array}$ & & \\
\hline Bribes for construction permits & & & & & $\begin{array}{c}0.776^{* * *} \\
(0.215)\end{array}$ & \\
\hline Bribes for govt. jobs & & & & & & $\begin{array}{c}1.036^{* * *} \\
(0.196)\end{array}$ \\
\hline Controls & Yes & Yes & Yes & Yes & Yes & Yes \\
\hline Commune Fixed Effects & Yes & Yes & Yes & Yes & Yes & Yes \\
\hline Mean of dep. var. & 5.02 & 5.02 & 5.02 & 5.02 & 5.02 & 5.02 \\
\hline $\mathrm{N}$ & 1318 & 1318 & 1318 & 1318 & 1318 & 1318 \\
\hline
\end{tabular}

Notes: This table uses data from the Vietnam Social Capital Survey (VSCS). Controls include age, gender, education, ethnicity, marital status, household assets, and household poverty status. The corruption variables are dummy variables that take value 1 if the respondent indicates agreement and 0 otherwise. Standard errors clustered at the commune level are reported in parentheses. ${ }^{*}$ significant at $10 \%,{ }^{* *}$ significant at $5 \%,{ }^{* * *}$ significant at $1 \%$. 


\section{Table A8: Detailed corruption measures and Severe Stress}

\begin{tabular}{|c|c|c|c|c|c|c|}
\hline & $(1)$ & $(2)$ & (3) & $(4)$ & $(5)$ & (6) \\
\hline Officials divert funds for private benefit & $\begin{array}{c}0.060^{*} \\
(0.031)\end{array}$ & & & & & \\
\hline Bribes for land titles & & $\begin{array}{c}0.026 \\
(0.026)\end{array}$ & & & & \\
\hline Bribes in hospitals & & & $\begin{array}{l}0.042^{* *} \\
(0.019)\end{array}$ & & & \\
\hline Bribes to school teachers & & & & $\begin{array}{c}0.048^{*} \\
(0.026)\end{array}$ & & \\
\hline Bribes for construction permits & & & & & $\begin{array}{c}0.021 \\
(0.022)\end{array}$ & \\
\hline Bribes for govt. jobs & & & & & & $\begin{array}{l}0.050^{* *} \\
(0.020)\end{array}$ \\
\hline Controls & Yes & Yes & Yes & Yes & Yes & Yes \\
\hline Commune Fixed Effects & Yes & Yes & Yes & Yes & Yes & Yes \\
\hline Mean of dep. var. & 0.12 & 0.12 & 0.12 & 0.12 & 0.12 & 0.12 \\
\hline $\mathrm{N}$ & 1318 & 1318 & 1318 & 1318 & 1318 & 1318 \\
\hline
\end{tabular}

Notes: This table uses data from the Vietnam Social Capital Survey (VSCS). Controls include age, gender, education, ethnicity, marital status, household assets, and household poverty status. Severe stress is an indicator for CES-D index $\geq 10$. The corruption variables are dummy variables that take value 1 if the respondent indicates agreement and 0 otherwise. Standard errors clustered at the commune level are reported in parentheses. ${ }^{*}$ significant at $10 \%,{ }^{* *}$ significant at $5 \%,{ }^{* *}$ significant at $1 \%$. 